\title{
Angio-pathological appearances of pulmonary valve in pulmonary atresia with intact ventricular septum Interpretation of nature of right ventricle from pulmonary angiography
}

\author{
ELIZABETH A BRAUNLIN, AUGUSTIN G FORMANEK, JAMES H MOLLER, JESSE E \\ EDWARDS
}

From the Dwan Cardiovascular Learning Center and the Departments of Pediatric Cardiology, Radiology, and Pathology, University of Minnesota, Minneapolis, and from the Department of Pathology, United Hospitals, St Paul, Minnesota, USA

SUMMARY Correlative angiographic-anatomical studies in 19 cases of pulmonary atresia with intact ventricular septum showed the following relations between the angiographic appearance of the pulmonary valve and the morphology of the right ventricle.

(1) Doming of the pulmonary valve was associated with a nearly normal-sized right ventricle and a wide infundibulum patent to the level of the pulmonary valve.

(2) A fixed valve was associated either with (a) pronounced hypoplasia of the ventricular chamber and stenosis of the infundibulum or (b) less commonly, a massive right ventricle and Ebstein's malformation of the tricuspid valve.

(3) An intermediate type valve was associated with a small right ventricle and a small infundibulum which was, however, patent to the level of the pulmonary valve.

It is suggested that the configuration of the pulmonary valve is a result of haemodynamic stresses placed upon it. These stresses, in turn, are determined by the morphological nature of the right ventricle. Thus, the nature of the pulmonary valve as seen angiographically may be used as an index of right ventricular morphology.

Infants with pulmonary atresia and intact ventricular septum are often critically ill and require urgent diagnosis and treatment in the neonatal period. ${ }^{1}$ The type of operation performed, whether pulmonary valvotomy or a combination of an aorto-pulmonary shunt and the creation of an atrial septal defect, is based upon angiographic determination of right ventricular size and morphology. ${ }^{2-5}$ Several authors have emphasised the variability of infundibular morphology and its importance in influencing the outcome of pulmonary valvotomy. ${ }^{5-8}$ In cases where the infundibulum is patent to the level of the pulmonary valve and the atretic valve takes the form of a thin diaphragm, surgical right ventricular to pulmonary artery continuity may be obtained more readily than

This study was supported by US Public Health Service Research grants from the National Heart, Lung and Blood Institute.

Accepted for publication 15 September 1981 in those instances of severe infundibular hypoplasia or atresia. ${ }^{458}$

Zuberbuhler and Anderson ${ }^{6}$ recently described the anatomical characteristics of the pulmonary valve in their necropsy specimens of pulmonary atresia with intact ventricular septum; there were two distinct appearances. In the first type, "prominent commissural ridges converged and met at the centre of the 'valve'", while in the second type the commissural ridges were "present only at the periphery of the membranous pulmonary valve, the centre being smooth and bulging into the pulmonary trunk". Additionally, they found that the first type of pulmonary valve "was invariably associated either with infundibular atresia or with a severely stenotic or regurgitant tricuspid valve". Using this as a basis, we have attempted to correlate the angiographic appearance of the pulmonary valve, not only with its anatom- 
ical appearance, but also with the underlying right ventricular and infundibular morphology. Such a correlation, if available, would be of considerable clinical interest, since it would distinguish between infants in whom pulmonary valvotomy alone might be inadequate to establish right ventricular to pulmonary arterial continuity and those in whom continuity could be easily established and right ventricular growth encouraged.

The purpose of this study, therefore, was to determine whether the angiographic character of the pulmonary valve in cases of pulmonary atresia with intact ventricular septum was a reliable basis from which to predict the size and morphology of the right ventricular chamber.

\section{Subjects and methods}

The following observations were made: (1) the nature of the pulmonary valve as seen in angiocardiograms; (2) the nature of the pulmonary valve in necropsy specimens; (3) the size and morphology of the right ventricular chamber in angiocardiograms; and finally (4) the size and morphology of the right ventricle and tricuspid valve in necropsy specimens.

To determine the nature of the pulmonary valve angiographically, use was made of the lateral views of those left ventriculograms, aortograms, or the late phase of venous angiograms that showed the base of the pulmonary trunk. Angiograms from 27 patients were available for review, and in 19 of these the base of the pulmonary trunk was clearly seen angiographically (nine aortograms, four left ventriculograms, three pulmonary arteriograms performed after aortopulmonary shunting procedure, one left atriogram, and two late phase venous angiograms). In the other eight patients in whom angiography had been done, the pulmonary valve was not well visualised because of either an insufficient amount of contrast material (an aortogram in two patients) or the fact that the valve was obscured by overlying cardiac structures (forward angiograms in six patients). In the 19 satisfactory angiograms, the pulmonary valve was classified angiographically by one of us (AGF) as domed, fixed, or an intermediate form. This part of the study was done with the knowledge that pulmonary atresia with intact ventricular septum was present but without that of other details of the cases.

$A$ domed valve was identified when, during ventricular systole, the valve plate was mobile and formed either a large domed or box-like bowing into the pulmonary trunk. Pulmonary valve sinuses were often visible at the base of the dome. With a fixed valve, the base of the pulmonary trunk did not change in shape during the cardiac cycle and consistently appeared as a "pouch". Pulmonary valve sinuses were identified in some but not all cases. An intermediate form of the valve was present when doming, though present, involved only a small central portion of the valves? plate. Well-formed valve sinuses were visible at the base of the pulmonary trunk.

Ten of the 19 patients with satisfactory angiograms $\frac{\overline{\bar{F}}}{\frac{1}{\sigma}}$ had eventually died. Using the eight necropsy speci- $\stackrel{\mathbb{Q}}{\Omega}$ mens available from these cases we compared the angiographic characteristics of the pulmonary valve $\vec{\oplus}$ with its anatomical appearance. In five specimens the ${ }^{\circ}$ pulmonary valve had not been operated upon. In two $\vec{\omega}$ specimens (each with a fixed valve), an eccentrically $\stackrel{\omega}{S}$ placed single incision pulmonary valvotomy had been performed but each of these two valves could be easily reapproximated and the details of the anatomy deter- $-\dot{\omega}$ mined. In the final necropsy specimen (that with a i domed valve), though a small portion of pulmonary $\overrightarrow{-}$ valvular tissue had been surgically removed, it appeared that sufficient tissue remained intact in order to classify the valve.

The size and morphology of the right ventricle were $\stackrel{0}{\circ}$ determined by at least one of the following methods in each of the 19 cases: right ventriculography (15 cases), $\vec{\oplus}$ necropsy (eight cases), at operation (one case). In five? cases both the right ventriculogram and the necropsy specimen were available.

The available right ventriculograms were analysed for the presence and size of the infundibulum, the presence of myocardial sinusoids, the size of the $\stackrel{\frac{\Omega}{\Phi}}{\complement}$ inflow portion of the right ventricle, and the presence $\vec{\overrightarrow{ }}$ of tricuspid regurgitation.

In the eight necropsy specimens, the diameter of the infundibular chamber was measured by calibrated sound. Right ventricular and left ventricular inlet and outlet dimensions were measured as previously described $^{6}$ and were compared with previously published age-related normal values. ${ }^{9}$ A right $\frac{\sigma}{3}$ ventricular/left ventricular index was obtained by multiplying right ventricular inlet and outlet dimen- $\frac{\rho}{3}$ sions and dividing this product by the product of left ventricular inlet and outflow dimensions. ${ }^{6}$

Difficulties were encountered in measuring the very $\frac{?}{0}$ smallest ventricles with confidence. Though we remeasured these chambers on subsequent occasions ${ }_{\sigma}$ and were satisfied that we could reproduce our figures, it is possible that the size of the very smallest right ventricles has been overestimated because of $\omega$ the presence of myocardial sinusoids in these specimens.

The circumference of the true tricuspid valve ${ }_{\infty}^{\Phi}$ annulus was measured in each case and compared ${ }^{+}$ with previously published age-related normal values. ${ }^{9} \frac{0}{0}$ The circumference of the pulmonary trunk immedi- $\frac{\vec{D}}{\mathrm{D}}$ ately proximal to its bifurcation was measured in each $\frac{\rho}{\mathrm{O}}$ specimen.

The tricuspid valve was examined where possible in 
each of the eight specimens for Ebstein's malformation and for dysplasia of the valve. Tricuspid valve dysplasia was characterised as previously described by Becker and associates ${ }^{10}$ and included focal or diffuse thickening of the valve leaflets, deficient development of chordae and papillary muscles, improper separation of the valve components from the ventricular wall, and focal agenesis of valvular tissue.

\section{Results}

\section{DOMED PULMONARY VALVE}

In four of the 19 angiocardiographic studies (cases 1 to 4) the pulmonary valve appeared "domed" (Fig. 1a). The central part of the valve plate was mobile and smooth and bulged forward into the pulmonary trunk during ventricular systole. The angiographic appearance of the valve was similar to classical critical pulmonary valvular stenosis except that a jet was not identified. Necropsy in two of the four patients with domed valves who died showed the pulmonary valve to have the following characteristics (Fig. 1b).

The atretic pulmonary valve plate was thin and dome-shaped. On its arterial aspect were three shallow, thick, equidistant raphes, each terminating at the central part of the plate. Three well-formed sinuses were present.

The circumferences of the pulmonary trunks were 18 and $20 \mathrm{~mm}$, respectively.

Three of the four patients with a domed pulmonary

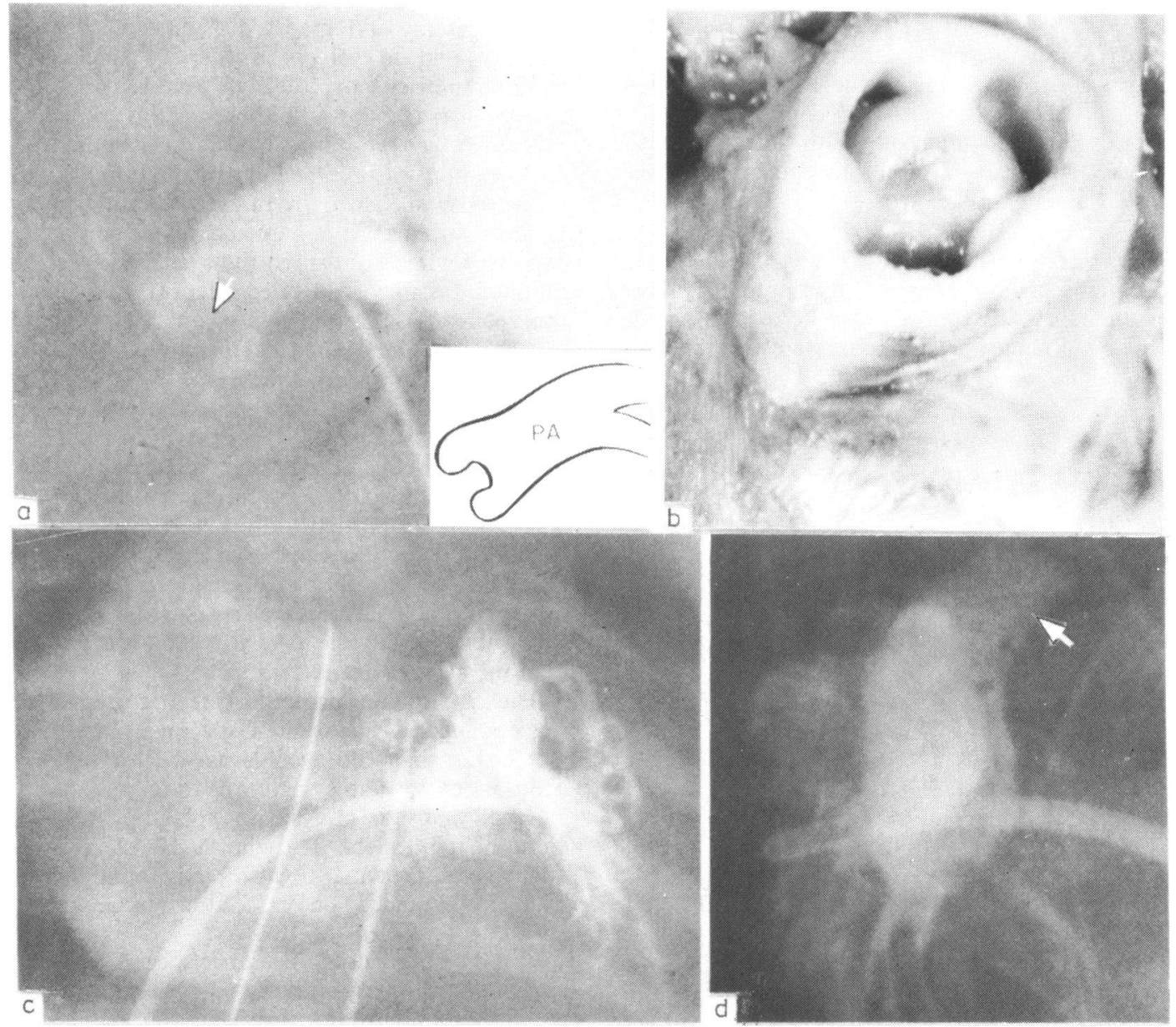

Fig. 1 Domed pulmonary valve in pulmonary atresia with intact ventricular septum. (a) Pulmonary arteriogram, lateral view. Pulmonary valve domed (arrow) into pulmonary trunk. Insert. Line drawing of pulmonary trunk as seen in accompanying angiogram. (b) Specimen of domed pulmonary valve from above. (c) and (d) Right ventriculogram, anteroposterior view (c) and lateral view (d). Right ventricle smaller than normal. Infundibulum patent to level of pulmonary valve (arrow). 
valve had had right ventriculograms. In each, the right ventricular inflow portion was highly trabeculated and of nearly normal size. "Significant" tricuspid regurgitation was present in each, though part of this regurgitation may have been catheter-induced. Myocardial sinusoids were not seen. The infundibulum was of normal calibre and appeared patent to the level of the pulmonary valve in each case (Fig. $1 c$ and d).

In the two available necropsy specimens with a domed pulmonary valve, analysis of the right ventricle disclosed the following characteristics. The infundibulum admitted a 2 to $3 \mathrm{~mm}$ probe, and the probe could be advanced to the pulmonary valve. Right and left ventricular dimensions were within the limits of normal for age, ${ }^{9}$ but the right ventricular/left ventricular indices of 0.58 and 0.81 disclosed the relative hypoplasia of the right ventricle in these cases (Fig. 2).

The circumference of the tricuspid valve annulus in both specimens was below the average age-related value. ${ }^{9}$ Neither specimen showed gross evidence of Ebstein's malformation, but both showed signs of dysplasia, consisting of focal thickening of the leaflets and shortened chordae.

\section{FIXED PULMONARY VALVE}

Angiograms of nine patients (cases 5 to 13) showed the pulmonary valve to be of the "fixed" type (Fig. 3a). The pulmonary arterial root retained a pouch-like

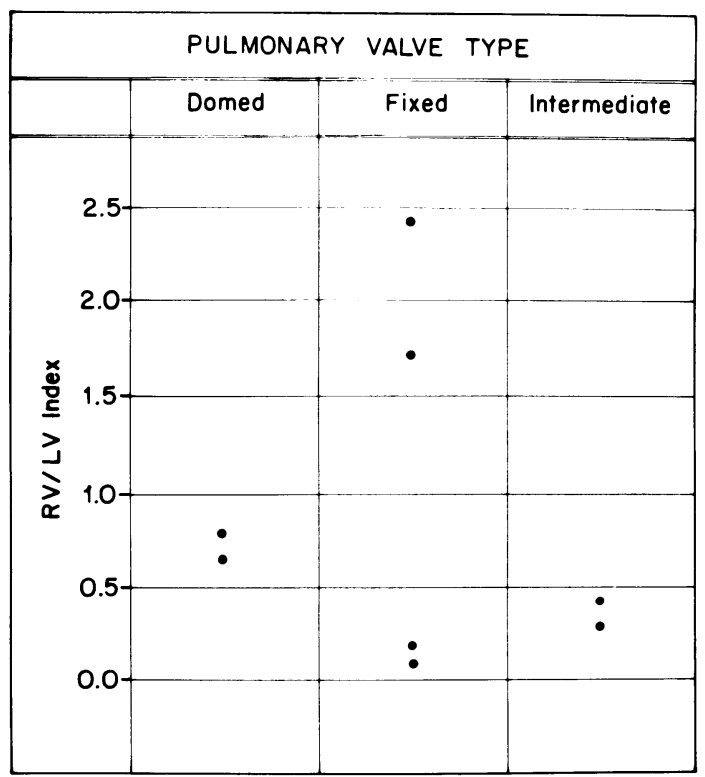

Fig. 2 Right ventricular/left ventricular indices determined for all necropsy specimens with pulmonary atresia and intact ventricular septum. Cases grouped by valve type. shape throughout the cardiac cycle, and no doming of the valve was seen. Five patients in this group died, $\stackrel{ }{\vec{\Rightarrow}}$ and necropsy specimens were available in four of $\stackrel{\vec{\rho}}{\rightarrow}$ these cases. In each specimen the base of the pulmo- 0 nary trunk appeared primitive and poorly defined $\overline{\underline{V}}$ (Fig. 3b). The valve plate was a flat firm membrane. $\frac{\bar{\omega}}{\bar{D}}$ Upon its arterial aspect two or three thin ridges con- $\stackrel{\mathbb{D}}{\propto}$ verged to meet at the centre of the valve plate. The of pulmonary valve sinuses were poorly formed.

The circumference of the pulmonary trunk ranged $\stackrel{\circ}{\circ}$ from 14 to $24 \mathrm{~mm}$.

In seven of the nine patients with a fixed valve, $\mathrm{a} \stackrel{\omega}{\mathscr{\omega}}$ right ventriculogram was available. From these, two distinct types of ventricular morphology were found. In two patients the right ventricle was much enlarged $\omega$ and associated with massive tricuspid regurgitation $N_{\infty}$ (Fig. 4a and b). The infundibular chamber in each was $\rightarrow$ widely patent, and myocardial sinusoids were not demonstrated. In each of the other five patients with a fixed pulmonary valve the right ventricular chamber 3 was minute and the infundibulum tiny. Myocardial sinusoids were prominent in each case, and tricuspid regurgitation was minimal or absent (Fig. $4 c$ and d). $\stackrel{\odot}{\infty}$

Necropsy specimens were available in four of the? patients with a fixed pulmonary valve. In each of the two cases with an enlarged right ventricle the infundibulum was a poorly defined extension of the body of $\frac{\bar{O}}{\mathrm{O}}$ this chamber. Measured right ventricular dimensions exceeded the limits of normal for age-related controls, $\underset{\varnothing}{\stackrel{\Phi}{\varnothing}}$ while left ventricular dimensions were within the $\overrightarrow{\vec{B}}$ normal range. ${ }^{9}$ The right ventricular/left ventricular 3 indices of 2.45 and 1.71 (Fig. 2) indicated the degree $\bar{F}$ of right ventricular enlargement. Ebstein's malforma-c. tion of the tricuspid valve was present in both cases. The atrialised portion of the right ventricle was significant in each specimen. Nevertheless, in contrast to cases with isolated Ebstein's malformation, the true 3 right ventricular chamber, as measured from the base of the abnormal tricuspid valve leaflet, was also larger $\frac{}{3}$ than the average age-related value. ${ }^{9}$

The circumference of the true tricuspid annulus 3 was obtained in each of these specimens, and in both $\frac{}{2}$ was larger than the average age-related value. ${ }^{9}$ In $=$ addition to Ebstein's malformation, each tricuspid valve showed signs of dysplasia, including focal thick- $N$ ening of the leaflets, deficient chordal development, N attachment of valvular tissue directly to the right ven- $\omega$ tricular wall, and, in one case, focal agenesis of valvular tissue.

In the two remaining necropsy specimens with the angiographic appearance of a fixed pulmonary valve,, the infundibulum was very stenotic, and a $2 \mathrm{~mm}_{-}^{-}$ probe could not be advanced into it, there being mus- $\frac{\Phi}{\Phi}$ cular obstruction between it and the pulmonary valve. $\frac{?}{8}$

Right ventricular dimensions were abnormally small, while left ventricular dimensions were withine 


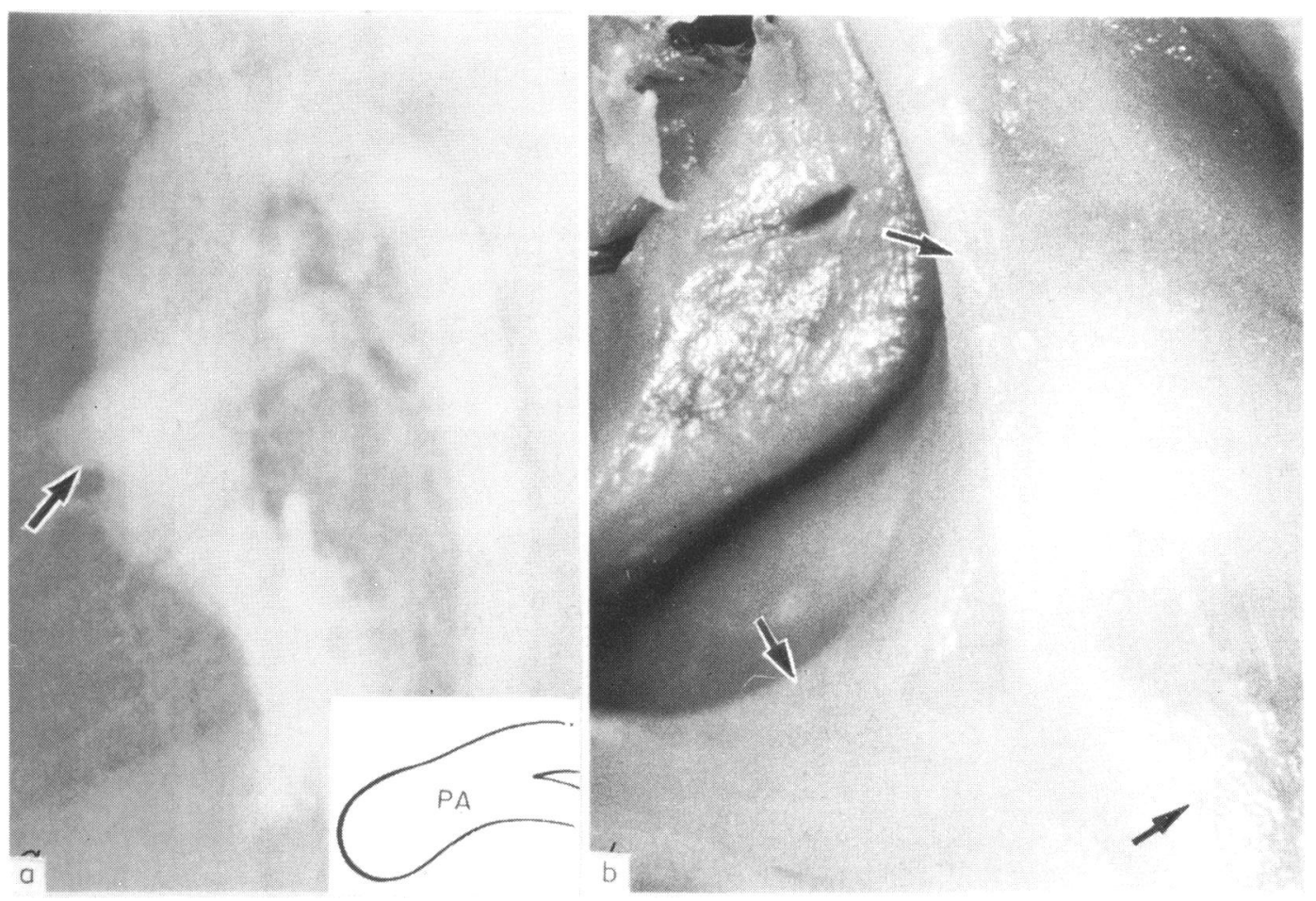

Fig. 3 Fixed pulmonary valve in pulmonary atresia with intact ventricular septum. (a) Left ventriculogram, lateral view. Pulmonary arterial root appears as a fixed single pouch-like sac (arrow) during ventricular systole. Neither valve sinuses nor central area of doming are present. Insert. Line drawing of pulmonary trunk as seen in accompanying angiogram. (b) Specimen of fixed type of pulmonary valve from above. Three raphes (arrows) meet in centre of valve plate.

normal limits and the right ventricular/left ventricular indices were 0.19 and 0.11 , reflecting the extreme hypoplasia of the right ventricle (Fig. 2).

In one survivor of the group with the fixed type of valve no right ventriculogram was performed, but at operation a very hypoplastic tricuspid valve and right ventricle were seen.

The circumference of the tricuspid valve annulus was measured in each case and found to be less than the average age-related value. ${ }^{9}$ Severe tricuspid valve dysplasia was present in both specimens and consisted of thickened valve tissue, abnormal chordae and papillary muscles, and focal agenesis of valvular tissue.

\section{INTERMEDIATE PULMONARY VALVE}

From angiograms in the remaining six cases (cases 14 to 19), the pulmonary valve was classified as of the "intermediate" type. The valve sinuses were well formed. A small area of separation was seen between the sinuses centrally. During ventricular systole the area of separation widened and the tiny central portion of the atretic valve plate domed (Fig. 5a). Three patients died, and specimens were available from two. In both, the pulmonary valve bore a strong resemblance to the domed pulmonary valve in that three thick ridges or raphes were present but did not extend to the centre of the valve plate. The central area of the valve was smooth and thin but, in contrast to the classical domed valve, formed only a small portion of the total valve surface (Fig. 5b).

The circumferences of the pulmonary trunks were 18 and $26 \mathrm{~mm}$, respectively. In four of the five patients with an intermediate type of pulmonary valve, right ventriculograms were available for study. In each case the inflow portion of the right ventricle was small. The infundibulum was present and appropriate for the size of the ventricle but appeared smaller than normal (Fig. 5c and d). Myocardial sinusoids were seen in two of the right ventriculograms, but in the other two their presence could not be determined. Tricuspid regurgitation was mild in each case. Three patients from this group died, and necropsy specimens were available in two. A $2 \mathrm{~mm}$ probe could be advanced into each infundibulum to the level of the pulmonary valve. Right ventricular dimensions 

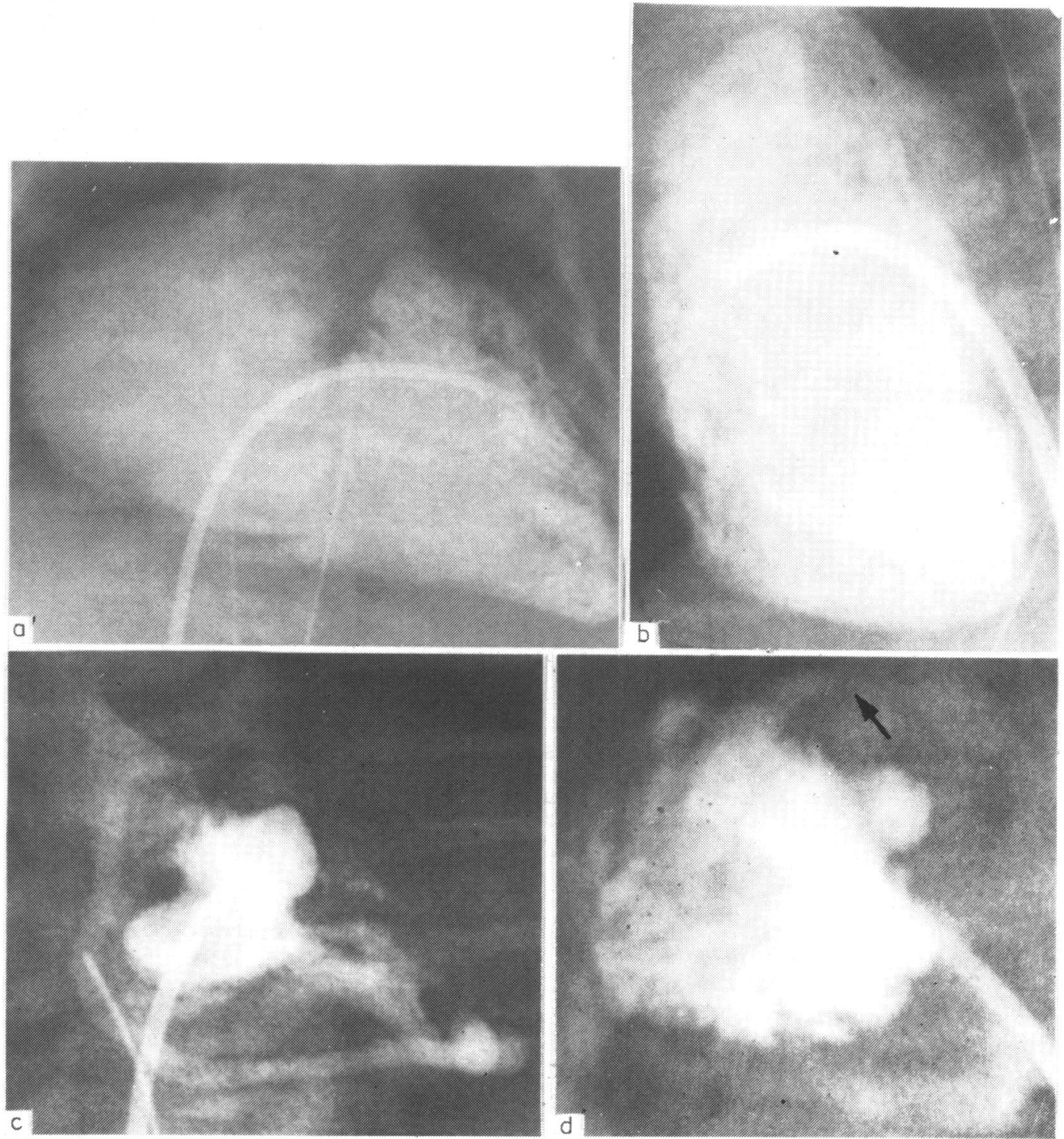

Fig. 4 Two cases of pulmonary atresia with fixed type of pulmonary valve. $(a)$ and $(b)$ Enlarged right ventricle and tricuspid regurgitation. Right ventriculogram in frontal view (a) and lateral view $(b) .(c)$ and $(d)$ Minute right ventricle. (c) Frontal view shows prominent myocardial sinusoids through which opacification of the aorta occurs. (d) Lateral view. Hypoplastic infundibulum (arrow).

were smaller than the average age-related normal values, but left ventricular dimensions were within normal limits. ${ }^{9}$ The right ventricular/left ventricular indices of 0.42 and 0.32 were intermediate between the values in those specimens with a tiny right ventricle and fixed pulmonary valve, and those with a nearly normal ventricular size and domed pulmonary valve $T$ (Fig. 2).

The circumference of the tricuspid valve annulus was measured in both specimens and was found to be less than the average value but still within the range of $\sigma$ normal for age-related controls. ${ }^{9}$ Tricuspid valve dys- 

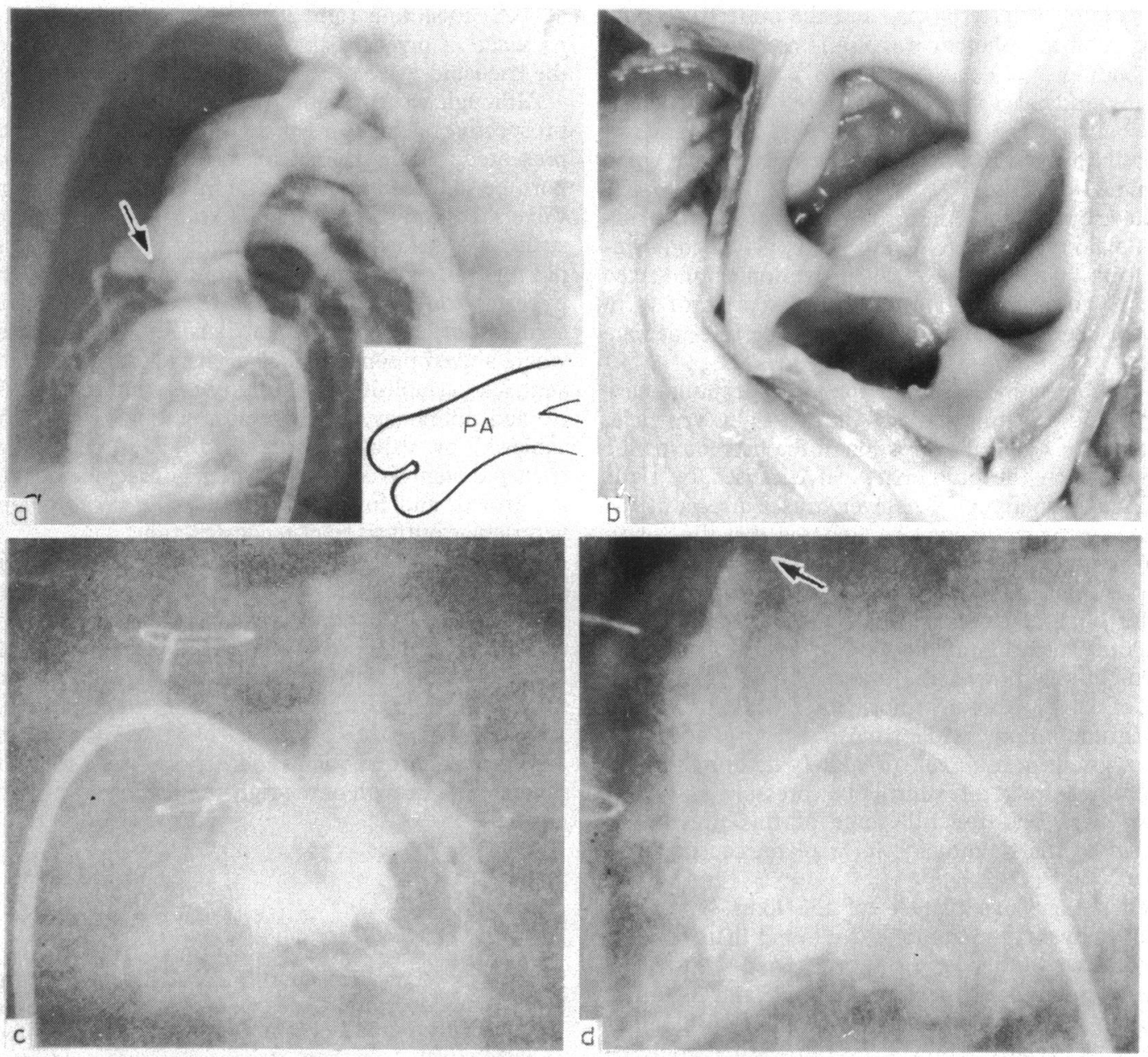

Fig. 5 Intermediate type of pulmonary valve in pulmonary atresia with intact ventricular septum. (a) Left ventriculogram, lateral view. Two well-formed pulmonary valve sinuses are seen, the posterior sinus being partially obscured by the overlying ascending aorta and coronary artery. A tiny central dome separates the valve sinuses (point of arrow). Insert. Line drawing of pulmonary trunk as seen in accompanying angiogram. (b) Specimen of intermediate type pulmonary valve viewed from above. (c) and (d) Right ventriculogram, anteroposterior view (c) and lateral view (d). Right ventricle small. Infundibulum patent to level of pulmonary valve (arrow).

plasia was present in both specimens, consisting of abnormal chordae and thickened leaflets in one case and an arcade-like tricuspid valve in the other.

\section{Comment}

This study confirmed the general concepts of Zuberbuhler and Anderson ${ }^{6}$ that in pulmonary atresia with intact ventricular septum there is variation in the structure of the pulmonary valve and, moreover, that there is a tendency for certain structural types of pulmonary valve to be associated with particular right ventricular features.

Additionally, the direct relation between the circumference of the tricuspid valve annulus and the right ventricular chamber size reported in this study, as well as the finding of some degree of tricuspid valve dysplasia in all specimens, supports the conclusions not only of Zuberbuhler and Anderson but also of others. ${ }^{11}$ That no correlation could be found between 
the pulmonary arterial size and the underlying right ventricular morphology was also in accord with previous findings. ${ }^{6}$

This study also showed that there is a close correlation between the angiocardiographic appearance of the pulmonary valve and the state of the valve when examined directly.

Zuberbuhler and Anderson ${ }^{6}$ designated two structural main types of atretic pulmonary valves conforming to the types we have called the domed and fixed types. Our observations indicate that a third form may be identified angiographically, the intermediate type.

The correlation between the type of pulmonary valve, and the morphology of the right ventricle, seems to be a logical expression of the haemodynamic stresses upon the pulmonary valve caused by right ventricular anatomy. Whatever causes atresia of the pulmonary valve, it may be assumed that the condition is established early in embryonic life. Thus, stresses upon the valve plate occur for many months before birth and these stresses have an influence in moulding its structure.

Our study showed the association of the domed type of valve with a near-normal sized right ventricle and infundibulum, while tricuspid regurgitation was either absent or minimal. It is likely that under these conditions the right ventricular pressure is abnormally high, and the full force of this pressure is applied to the pulmonary valve plate, causing it to dome.

When the valve plate is of the fixed type, represented by a flat membrane, we found that the right ventricle was either large and associated with tricuspid regurgitation or the right ventricle and its infundibulum were hypoplastic. Under either of these circumstances relatively low levels of pressure would be applied to the valve plate, leaving it in a non-domed state.

The intermediate type of valve is characterised by minimal doming and in this type it is reasonable that the haemodynamics of the right ventricle are intermediate between those associated with the domed and fixed types of valve.

Thus, it appears evident that the appearance of the pulmonary valve plate is a consequence of stresses upon it, and the anatomical nature of the right ventricle determines the haemodynamics which, in turn, influence the valve configuration.

From the clinical point of view, this concept may be helpful, as from a given configuration of the pulmonary valve, subvalvular haemodynamics may be inferred. From the latter, in turn, a concept of right ventricular morphology may be assumed, though the potential for right ventricular growth after pulmonary valvotomy may also depend upon several other factors

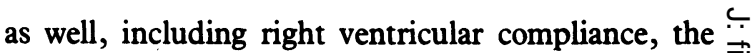
presence of myocardial sinusoids, and the nature of the tricuspid valve.

Although we have not used this classification in a $\frac{}{}$ prospective fashion, we believe, from the evidence $\frac{\bar{c}}{\bar{p}}$ presented, that a pulmonary valvotomy in the new- $\stackrel{\varnothing}{\circ}$ born period in an infant with a fixed type pulmonary valve should probably be avoided. In the cases where such a valve exists with a large right ventricle, tricus- $?$ pid regurgitation in concert with neonatal pulmonary $\overrightarrow{\vec{\omega}}$ hypertension may, as others have noted, 612 result in $\stackrel{D}{\circ}$ cardiac output inadequate to sustain life. In cases where a fixed pulmonary valve exists with a tiny right + ventricle, establishing continuity between the ventri- $\dot{\omega}$ cle and pulmonary artery almost certainly cannot be $\sim_{\infty}$ achieved by valvotomy alone. In addition, severe $\stackrel{\infty}{\rightarrow}$ tricuspid stenosis and dysplasia may preclude adequ- $\frac{}{3}$ ate growth and function in spite of successful right ventricular outflow tract reconstruction.

On the other hand, in cases of pulmonary atresia $\frac{0}{3}$ and intact ventricular septum where the pulmonary valve appears to be either domed or "intermediate", $a \stackrel{\oplus}{\oplus}$ valvotomy in the newborn period appears technically $N$ feasible, either alone or together with an aortopulmonary shunting procedure. In addition, right ventricular chamber size in both of these categories approaches normal values more closely and thus the potential for growth of the right ventricle may be anti- $\stackrel{\otimes}{\Omega}$ cipated.

\section{References}

1 Gersony WM, Bernhard WF, Nadas AS, Gross RE. ֻ Diagnosis and surgical treatment of infants with criticalo pulmonary outflow obstruction. Study of thirty-four infants with pulmonary stenosis or atresia, and intacto ventricular septum. Circulation 1967; 35: 765-76.

2 Dhanavaravibul S, Nora JJ, McNamara DG. Pulmonary valvular atresia with intact ventricular septum: problems $\supset$ in diagnosis and results of treatment. $\mathcal{F}$ Pediatr 1970; 77: 1010-6.

3 Luckstead EF, Mattioli L, Crosby IK, Reed WA, Diehlin AM. Two-stage palliative surgical approach for pulmonary atresia with intact ventricular septum (type I). Am $\mathcal{F}^{\mathrm{N}}$ Cardiol 1972; 29: 490-6.

4 Cole RB, Muster AJ, Lev M, Paul MH. Pulmonaryo atresia with intact ventricular septum. Am $\mathcal{F}$ Cardiol 1968; 21: 23-31.

5 Dobell ARC, Grignon A. Early and late results in pul- $\bar{\Phi}$ monary atresia. Ann Thorac Surg 1977; 24: 264-74.

6 Zuberbuhler JR, Anderson RH. Morphological variations in pulmonary atresia with intact ventricular sep-? tum. Br Heart $\mathcal{F}$ 1979; 41: 281-8.

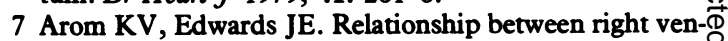
tricular muscle bundles and pulmonary valve. $\sigma$ Significance in pulmonary atresia with intact ventriculat septum. Circulation 1976; 54, suppl III: 79-83. 
8 Patel RG, Freedom RM, Moes CAF, et al. Right ventricular volume determinations in 18 patients with pulmonary atresia and intact ventricular septum. Analysis of factors influencing right ventricular growth. Circulation 1980; 61: 428-40.

9 Rowlatt UF, Rimoldi HJA, Lev M. The quantitative anatomy of the normal child's heart. Pediatr Clin North Am 1963; 10: 499-588.

10 Becker AE, Becker MJ, Edwards JE. Pathologic spectrum of dysplasia of the tricuspid valve. Features in common with Ebstein's malformation. Arch Pathol 1971; 91: 167-78.

11 Freedom RM, Dische MR, Rowe RD. The tricuspid valve in pulmonary atresia and intact ventricular septum. A morphological study of 60 cases. Arch Pathol 1978; 102: 28-31.

12 Barr PA, Celermajer JM, Bowdler JD, Cartmill TB. Severe congenital tricuspid incompetence in the neonate. Circulation 1974; 49: 962-7.

Requests for reprints to Dr Jesse E Edwards, Department of Pathology, United Hospitals, 333 North Smith Avenue, St Paul, Minnesota 55102, USA 